\title{
A Comparative Study on Removal of Toluene by Batch Reactor using Different Fungal Culture Isolated from Municipal Sewage Water
}

\author{
S. Bhuvaneswari, A.G. Deepa Priya, A.R. Dhayananda Shakar, C.S. Sharath Kumar, M. Gopinath \\ and R. Dhanasekar
}

\begin{abstract}
The increasing rate of polluted gases in the atmosphere raises some of the major environmental and human health related problems that was recently suspected; hence the comparative study on removal of toluene by batch reactor using different fungal culture helps to minimize the toluene gas in the atmosphere. The comparative study on toluene removal was investigated by various parameters such as effect of different fungal culture with its characterization and effect of concentration. After startup the batch reactor was kept in a shaker with $150 \mathrm{rpm}$ for five days with the synthetic effluent, prepared with Toluene concentration of about $1 \%$ was used for the entire study. The treated effluent was analyzed by GC - FID for Toluene degradation and was found to be $75 \%$ (the environmental conditions were maintained by $\mathrm{pH} 7$ and $30^{\circ} \mathrm{C}$ ) by Penicillium sp. greater than the Aspergillus niger and Trichoderma viride. A single cycle of two weeks provided degradation rate of about $92 \%$. This provides further scope for experimentation which will be useful in developing the continuous removal of toluene by successive batch reactor or continues reactor.
\end{abstract}

Keywords--- Toluene, Batch Reactor, Atmosphere, Human Health, Toxic Gases

\section{INTRODUCTION}

A $\mathrm{T}$ the present epoch emission of lethal substances has become a major threat to the harmonic approach of bio systems. Toluene is one of the major noxious volatile organic compounds that act as a type two carcinogenic agent. The

S. Bhuvaneswari, Department of Biotechnology, Karpaga Vinayaga College of Engineering and Technology, Madhranthagam, Taminadu, India. E-mail:buvibtech@gmail.com

A.G. Deepa Priya, Department of Biotechnology, Karpaga Vinayaga College of Engineering and Technology, Madhranthagam, Tamilnadu, India. E-mail: dpriya.bt91@gmail.com

A.R. Dhayananda Shakar, Department of Biotechnology, Karpaga Vinayaga college of Engineering and Technology, Madhranthagam, Tamilnadu, India. E-mail: dhayanandashakar@gmail.com

C.S. Sharath Kumar, Department of Biotechnology, Karpaga Vinayaga College of Engineering and Technology, Madhranthagam, Tamilnadu, India. E-mail: shharaa@gmail.com

M. Gopinath, Assistant Professor, Department of Biotechnology, Karpaga Vinayaga College of Engineering and Technology, Madhranthagam, Tamilnadu, India. E-mail: mpgopinath1980@ gmail.com

R. Dhanasekar, Professor, Department of Chemical Engineering, FEAT, Annamalai University, Chidambaram, Tamilnadu, India. E-mail: rdhanasekar26@rediffmail.com name toluene was derived from the older name toluol, which refers to tolu balsam, which was first secluded from Myroxylon balsamum. It was originally named by Jons Jakob Berzelius. Toluene $(\mathrm{C} 7 \mathrm{H} 8)$ is an aromatic hydrocarbon belonging to the BTEX group of hazardous volatile organic compounds (VOC). Carbon - carbon bond lengths of the ring carbons in toluene are all the same length with an approximation of $0.1397 \mathrm{~nm}$, this accounts for the stabilization energy of $163.2 \mathrm{~kJ} / \mathrm{mol}$ and the structure shown in Figure. 1.

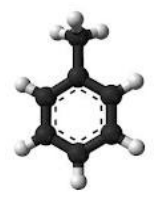

Figure 1: Structure of Toluene

Toluene is a common solvent, which can dissolve paints, paint thinners, silicone sealants, many chemical reactants, rubber, printing ink, glues, lacquers, leather tanners, and disinfectants. It can also be used as a fullerene indicator, and is a raw material for toluene diisocyanate (used in the manufacture of polyurethane foam) and TNT. Even though toluene possesses positive reassuring facet, it also constrain certain environmental and health hazards [1] such as tiredness, confusion, memory loss, and nausea, loss of appetite, and hearing and color-vision loss. These symptoms usually disappear when revelation is stopped. Hence it is decisive to abolish toluene from atmosphere as toluene is included in the list of priority pollutants selected by Environmental Protection Agency [2] and also it is considered as a Title three toxic compound of the 1990 Clean Air Act Amendment proposed by USEPA [3]. Assorted techniques have been used for treating toluene like physiochemical and biological treatment, especially Bio filtration [4], Biodegradation [5], Thermal oxidation, catalytic oxidation [6]. Among them biological treatments convert toluene into carbon dioxide, water, salt and biomass that are eco-friendly and often thriftily viable [7]. The objective of our present study is to improve the efficiency of biodegradation of toluene using isolated fungal strain from municipal sewage water involving investigation with various parameters such as effect of different fungal culture and effect of concentration. The microbial degradation of toluene was carried out in a shake and flask or batch reactor and was kept in a shaker with $150 \mathrm{rpm}$ for seven days and the synthetic effluent and was prepared with Toluene concentration of about $1 \%$ was used for the entire study. The treated effluent which was analyzed by GC - FID for Toluene degradation. This provides further scope for experimentation which will be 
useful in developing the continuous removal of toluene by successive batch reactor or continues reactor.

\section{MAterials AND MethodS}

\section{A. Source of Micro-Organisms}

The aerated municipal sewage effluent (microbial sample) collected from Chennai Metropolitan Water Supply and Sewage Board's Domestic Effluent Treatment Plant situated at Koyambedu.

\section{B. Media and Culture Conditions for Toluene Degrading Strain}

\section{- Raw Fungal Culture (Petriplate)}

The strains are isolated from aerated municipal sewage effluent (microbial sample). Initially the raw fungal culture was cultivated in a petriplate which contains the culture medium having the following composition per liter: $20.0 \mathrm{~g}$ Malt extract, $1.0 \mathrm{~g}$ Peptone, 20.0g Dextrose and 20.0.g Agar with the controlled $\mathrm{pH}$ at 7.0 by the addition of $\mathrm{NaOH}(2.5 \mathrm{~N})$ or $\mathrm{H}_{2} \mathrm{SO}_{4}(2.5 \mathrm{~N})$ and temperature at $30^{\circ} \mathrm{C}$ for 3 days. The medium was sterilized at $121^{\circ} \mathrm{C}$ under 15 psi for $15 \mathrm{~min}$.

\section{- Toluene Degrading Fungal Culture}

The toluene degrading strains were cultivated from raw fungal culture in a petriplate which consists of the culture medium having the following composition per liter: $20.0 \mathrm{~g}$ Malt extract, $1.0 \mathrm{~g}$ Peptone, 20.0g Dextrose and 20.0.g Agar, along with varying concentration of $1 \mathrm{ml}, 2 \mathrm{ml}, 4 \mathrm{ml}, 6 \mathrm{ml}, 8 \mathrm{ml}$ and $10 \mathrm{ml}$ of Toluene with the controlled $\mathrm{pH}$ at 7.0 by the addition of $\mathrm{NaOH}(2.5 \mathrm{~N})$ or $\mathrm{H}_{2} \mathrm{SO}_{4}(2.5 \mathrm{~N})$ and temperature at $30^{\circ} \mathrm{C}$ for 3 days. The medium was sterilized at $121^{\circ} \mathrm{C}$ under 15 psi for $15 \mathrm{~min}$. The culture was periodically sub-cultured for every 30 days.

\section{Batch Reactor Studies}

The experiments were conducted in a batch process. The fungal strains were used for the microbial degradation of toluene. The culture inoculated into the medium has the following composition per liter: $20.0 \mathrm{~g}$ Malt extract, $1.0 \mathrm{~g}$ Peptone, $20.0 \mathrm{~g}$ Dextrose along with concentration of $1 \mathrm{ml}$ of Toluene with the controlled $\mathrm{pH}$ at 7.0 by the addition of $\mathrm{NaOH}(2.5 \mathrm{~N})$ or $\mathrm{H}_{2} \mathrm{SO}_{4}(2.5 \mathrm{~N})$ and temperature at $30^{\circ} \mathrm{C}$ for 7 days. The medium was sterilized at $121^{\circ} \mathrm{C}$ under 15 psi for 15 min and kept for incubation under aerobic condition. Readings were taken at periodical time-intervals and the samples were tested for toluene degradation and bio mass growth

\section{Quantification of Toluene}

Toluene concentration was indomitable by injection of $1 \mu 1$ of sample with a precision syringe or Hamilton gas tight syringe into a gas chromatograph unit (MAYURA, Hewlett Packard) equipped with a flame ionization detector (FID) using a $30 \mu \mathrm{m}$ capillary column (HP-1, cross linked methyl siloxane) equipped with a $10 \mathrm{~m} \times 0.5 \mathrm{~mm}$ AT- 1000 column [8]. The temperature programe for the oven was $100{ }^{\circ} \mathrm{C}$ for 0.5 min, $5{ }^{\circ} \mathrm{C} \mathrm{min}{ }^{-1}$ from 100 to $130{ }^{\circ} \mathrm{C}$ for $1 \mathrm{~min}^{-1}$, and $20{ }^{\circ} \mathrm{C}$ from 130 to $160^{\circ} \mathrm{C}$ for $2 \mathrm{~min}$ and the carrier gas was nitrogen at a $4.6 \mathrm{ml} . \mathrm{min}^{-1}$ flowrate. The temperatures of the injector and detector were $150{ }^{\circ} \mathrm{C}$ and $180{ }^{\circ} \mathrm{C}$ respectively and the toluene concentrations were quantified by compared with standard.

\section{RESULTS AND DiSCUSSION}

\section{A. Isolation of Strains}

In the study of isolation of strains, the $10^{-2}, 10^{-4}, 10^{-6}, 10^{-8}$ and $10^{-10}$ of dilution were used for aerated municipal sewage effluent collected from Chennai Metropolitan Water Supply and Sewage Board's Domestic Effluent Treatment Plant situated at Koyambedu, which is added $(1 \mu \mathrm{l})$ to each one of the five different petriplates consisting of solidified agar medium and uninoculated petriplate as the control. This is allowed to grow for 3 days at $30^{\circ} \mathrm{C}$ in an incubator. The cultures were periodically sub- cultured for every 30 days once and were shown in Figure. 2.

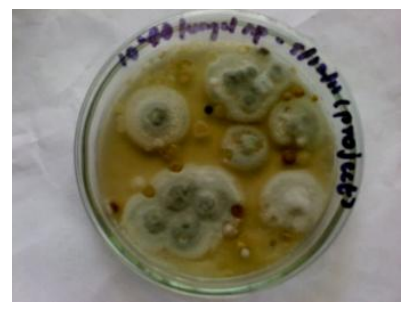

White Fungal Colonies

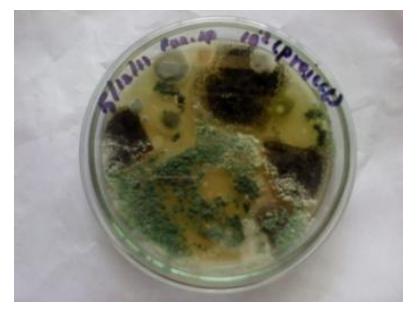

Green Fungal Colonies

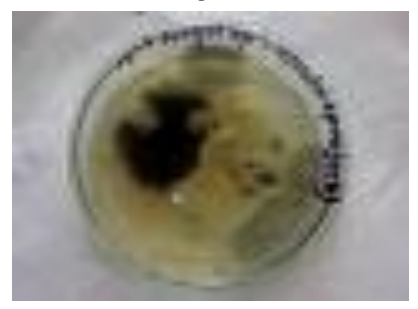

Black Fungal Colonies

Figure 2: Isolation of Fungal Strain

\section{B. Screening of Strains}

The screening of strains was studied by the earlier grown raw fungal culture and the pickup based on their dominant character was growing tendency in the petriplate. This provides selective three different colonies, inoculated in toluene incubated solid agar petriplate, which consist of solidified agar medium and uninoculated petriplate as the control. This is allowed to grow for 3 days at $30^{\circ} \mathrm{C}$ in an incubator. The culture was periodically sub cultured for every 30 days. The screening test was conducted with fungal characterization test (Lactophenol blue) based on their morphology which results in the identification of strain were shown below Figure.3. The degrading strain was screened from its group of colonies in raw fungal culture, which has the capability to degrade the Toluene containing sample. 


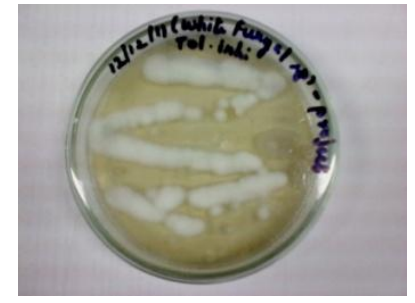

Toluene Degrading (Trichoderma viride)

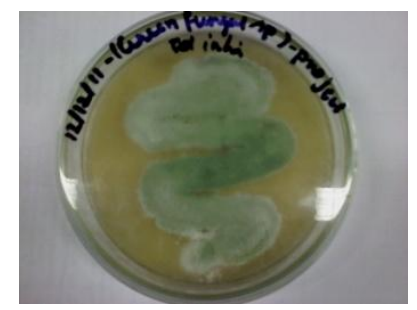

Toluene Degrading (Penicillium sp)

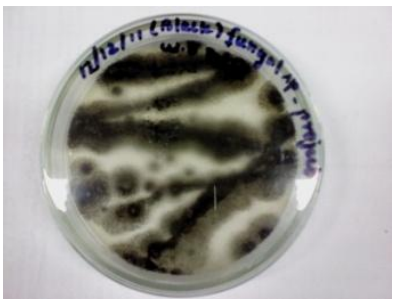

Toluene Degrading (Aspergillus niger)

Figure 3: Screening of Fungal Strain

\section{Batch Reactor Studies}

The batch reactor or shake and flask experiments were conducted in a batch process. The fungal strains were used for the microbial degradation of toluene. The culture was inoculated into the medium having the following composition per liter: 20.0g Malt extract, $1.0 \mathrm{~g}$ Peptone, 20.0g Dextrose and 20.0.g Agar, along with concentration of $1 \mathrm{ml}$ of Toluene with the controlled $\mathrm{pH}$ at 7.0 by the addition of $\mathrm{NaOH}(2.5 \mathrm{~N})$ or $\mathrm{H}_{2} \mathrm{SO}_{4}(2.5 \mathrm{~N})$ and temperature at $30^{\circ} \mathrm{C}$. The medium was sterilized at $121^{\circ} \mathrm{C}$ under $15 \mathrm{psi}$ for $15 \mathrm{~min}$ and kept for incubation under aerobic condition. Readings were taken at periodic time intervals and the samples were tested for toluene degradation and bio mass growth. The feed sample results of toluene concentration are shown in Figure. 1. taken from GC FID detecting toluene compounds at each one minute. For example in Figure. 4. it indicates the toluene at Retentions time $2.125^{\text {th }}$ minute. The peaks and total area $(299 \mathrm{mV} . \mathrm{s})$ indicates the amount of toluene present in feed was $0.15 \mathrm{mg} / \mathrm{ml}$ was tabulated in Table 1.

\section{- $\quad$ Toluene Degradation by Penicillium sp.}

In a shake and flask the Penicillium $s p$. was inoculated and it consisted of cultures medium with $1 \mathrm{ml}$ of toluene with the controlled $\mathrm{pH}$ at 7.0 by the addition of $\mathrm{NaOH}(2.5 \mathrm{~N})$ or $\mathrm{H} 2 \mathrm{SO} 4(2.5 \mathrm{~N})$ and temperature at $30^{\circ} \mathrm{C}$ for 7 days. The medium was sterilized at $121^{\circ} \mathrm{C}$ under 15 psi for $15 \mathrm{~min}$ and kept for incubation under aerobic condition. Samples were taken after $7^{\text {th }}$ day and the samples were tested for toluene degradation and bio mass growth. The toluene degradation by Penicillium sp. concentration results are shown in Figure 5 taken from GC - FID detecting. Toluene compounds at each one minute. For example in Figure 4 it indicates the toluene at Retentions time $2.125^{\text {th }}$ minute and peak area was $299 \mathrm{mV} \mathrm{s}$. Figure 5 indicates at Retentions time $2.125^{\text {th }}$ minute and peak area was $127 \mathrm{mV} \mathrm{s}$ was tabulated in Table. 2; hence the peak was periodically reduced to its original one and so the microbial degradation of toluene was found to be $75 \%$ for one week.

\section{- $\quad$ Toluene Degradation by Aspergillus Niger}

In a shake and flask the Asperegillus niger was inoculated and it consisted of cultures medium with $1 \mathrm{ml}$ of toluene with the controlled $\mathrm{pH}$ at 7.0 by the addition of $\mathrm{NaOH}(2.5 \mathrm{~N})$ or $\mathrm{H}_{2} \mathrm{SO}_{4}(2.5 \mathrm{~N})$ and temperature at $30^{\circ} \mathrm{C}$ for 7 days. The medium was sterilized at $121^{\circ} \mathrm{C}$ under 15 psi for $15 \mathrm{~min}$ and kept for incubation under aerobic condition. Samples were taken after $7^{\text {th }}$ day and the samples were tested for toluene degradation and bio mass growth. The results of toluene degradation by Aspergillus niger concentration are shown in Figure 6 taken from GC - FID detecting. Toluene compounds at each one minute. For example in Figure 4 it indicates the toluene at Retentions time $2.125^{\text {th }}$ minute and peak area was $299 \mathrm{mV}$ s. Figure 6 indicates at Retentions time $2.125^{\text {th }}$ minute and peak area was $157 \mathrm{mV} \mathrm{s}$ was tabulated in Table. 3; hence the peak was periodically reduced to its original one and so the microbial degradation of toluene using Aspergillus niger was found to be $65 \%$ for one week.

\section{- Toluene Degradation by Trichoderma viride}

In a shake and flask the Trichoderma viride was inoculated and it consisted of cultures medium with $1 \mathrm{ml}$ of toluene with the controlled $\mathrm{pH}$ at 7.0 by the addition of $\mathrm{NaOH}(2.5 \mathrm{~N})$ or $\mathrm{H}_{2} \mathrm{SO}_{4}(2.5 \mathrm{~N})$ and temperature at $30^{\circ} \mathrm{C}$ for 7 days. The medium was sterilized at $121^{\circ} \mathrm{C}$ under 15 psi for $15 \mathrm{~min}$ and kept for incubation under aerobic condition. Samples were taken after $7^{\text {th }}$ day and the samples were tested for toluene degradation and bio mass growth. The results of toluene degradation by Trichoderma viride concentration are shown in Figure 8 taken from GC - FID detecting. Toluene compounds at each one minute. For example in Figure 4 it indicates the toluene at Retentions time $2.125^{\text {th }}$ minute and peak area was $299 \mathrm{mV}$ s. Figure 7 indicates at Retentions time $2.125^{\text {th }}$ minute and peak area was $187 \mathrm{mV} \mathrm{s}$ was tabulated in Table. 4; hence the peak was periodically reduced to its original one and so the microbial degradation of toluene using Trichoderma viride was found to be $55 \%$ for one week.

\section{- Comparative Analysis of Microbial Degradation on} Toluene Using Different Fungal Strain

To estimate the degradation efficiency based on their removal capacity of three different dominant strains obtained from the toluene incubated petriplate were used for the isolation of culture inoculated in three different batch reactor or shake and flask used in this study and the results are shown in Figure 4, 5, 6 \& 7 taken from GC - FID detecting. Toluene compounds at each one minute. For example in Figure 4 it indicates the toluene at Retentions time $2.125^{\text {th }}$ minute and 
peak area was $299 \mathrm{mV}$ s. above all the graph the retention time for toluene compound was identical, but the peak area of the chromatogram was varying with respect to its degrading capacity. From Figure 5 the peak area was less than that of Figure 6 \& Figure 7 It indicates that the peak was periodically reduced to its original one and so the microbial degradation of toluene using Penicillium sp. shows very high degradation efficiency it was shown in Figure 8 and the peak area was tabulated in Table.5.

Table 1: Toluene Concentration in Feed Sample

\begin{tabular}{|c|c|c|c|}
\hline S.No & Time in min & Name & Area in $\mathrm{mV}$ \\
\hline 1 & 2.125 & Toluene & 299 \\
\hline
\end{tabular}

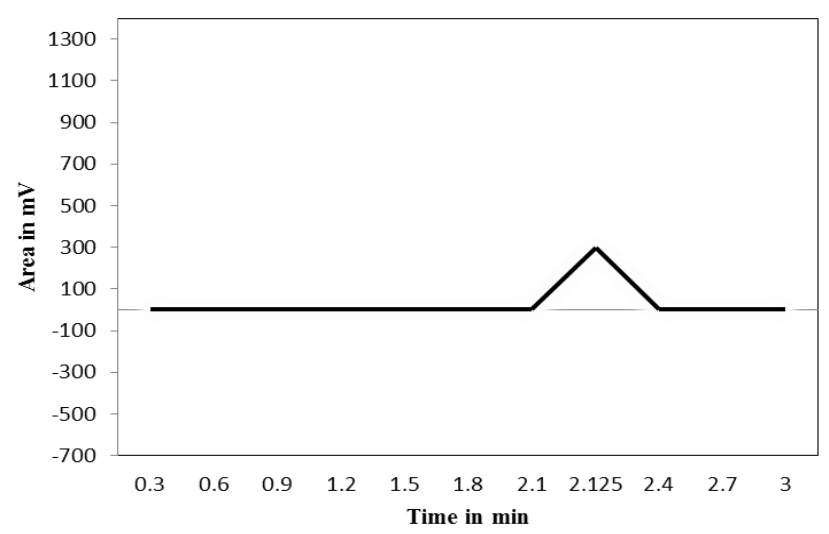

Figure 4: Toluene Concentration in Feed Sample

Table 2: Toluene Toluene Degradation by Penicillium sp

\begin{tabular}{|c|c|c|c|}
\hline S.No & Time in min & Name & Area in $\mathrm{mV}$ \\
\hline 1 & 2.125 & Toluene & 127 \\
\hline
\end{tabular}

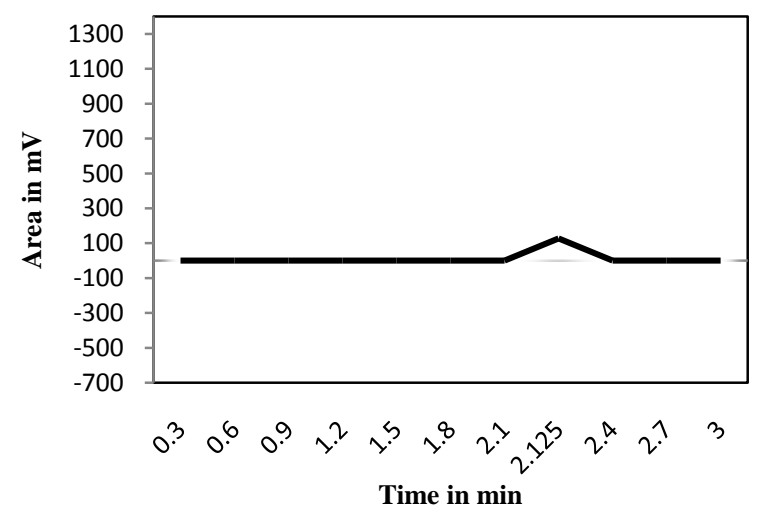

Figure 5: Toluene Toluene Degradation by Penicillium sp
Table 3: Toluene Degradation by Aspergillus Niger

\begin{tabular}{|c|c|c|c|}
\hline S.No & Time in min & Name & Area in $\mathrm{mV}$ \\
\hline 1 & 2.125 & Toluene & 182 \\
\hline
\end{tabular}

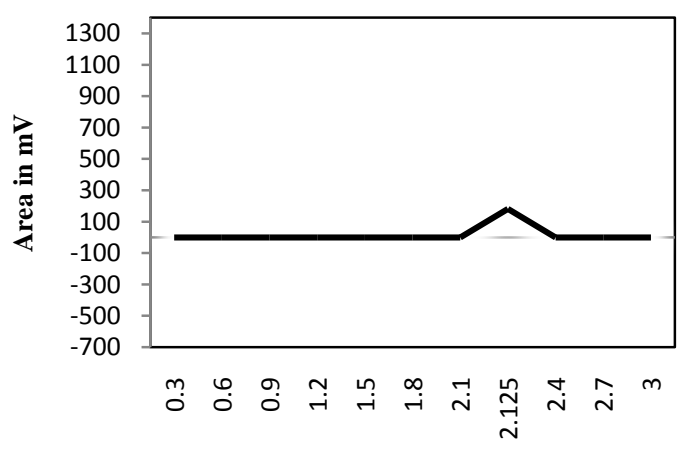

Time in min

Figure 6: Toluene Degradation by Aspergillus niger

Table 4: Toluene Degradation by Trichoderma viride

\begin{tabular}{|c|c|c|c|}
\hline S.No & Time in min & Name & Area in $\mathrm{mV}$ \\
\hline 1 & 2.125 & Toluene & 156 \\
\hline
\end{tabular}

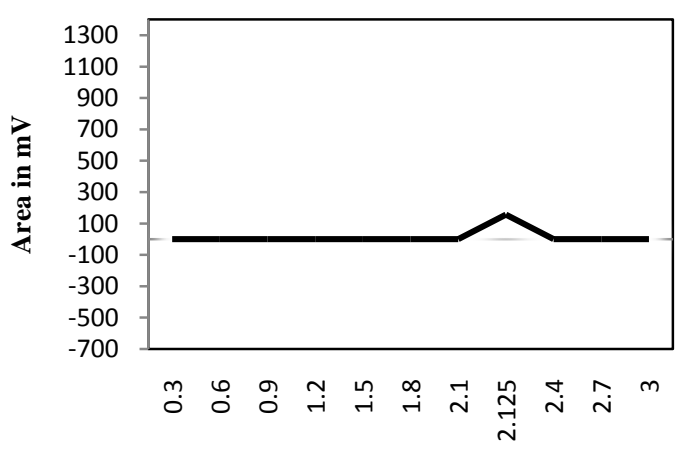

Time in min

Figure 7: Toluene Degradation by Trichoderma viride

Table 5: Microbial Degradation on Toluene Using Different Fungus Strain (Degradation Period: 7Days)

\begin{tabular}{|c|c|}
\hline Types of Fungus & Area in mV.s \\
\hline Penicillium $s p$ & 127 \\
\hline Aspergillus niger & 156 \\
\hline Trichoderma viride & 182 \\
\hline
\end{tabular}




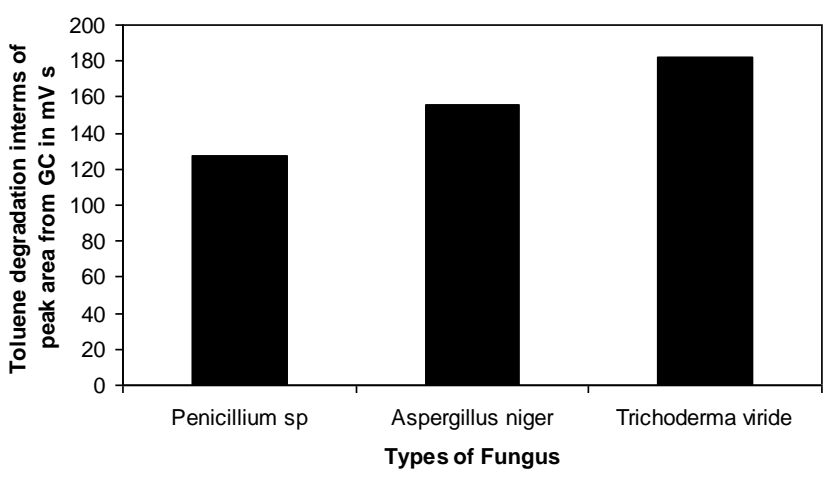

Figure 8: Microbial Degradation on Toluene Using Different Fungus Strain (Degradation Period: 7Days)

\section{CONCLUSION}

The comparative study on removal of toluene by batch reactor using different fungal culture isolated from municipal sewage water was investigated with various parameters such as effect of different fungal culture and effect of concentration. The microbial degradation of toluene was carried out in a shake and flask or batch reactor kept in a shaker with $150 \mathrm{rpm}$ for seven days with the synthetic effluent prepared with Toluene concentration of about $1 \%$ was used for the entire study. The treated effluent was analyzed by GC FID for Toluene degradation and was found to be $75 \%$ (the environmental conditions were maintained by $\mathrm{pH} 7$ and $30^{\circ} \mathrm{C}$ ) by Penicillium sp. greater than the Aspergillus niger and Trichoderma viride. A single cycle of two weeks provided degradation rate of about $92 \%$. This provides further scope for experimentation which will be useful in developing the continuous removal of toluene by successive batch reactor or continues reactor.

\section{ACKNOWLEDGEMENTS}

I express my sincere thank to the Management, Dean, Advisor, Principal and staff from the Department of Biotechnology, Karpaga Vinayaga college of Engineering and Technology for their support and encouragement in carrying out this work. The authors also wish to thank the staff from Department of Chemical Engineering, Annamalai University for their valuable suggestion and timely guidance for carrying out this work and also authors want to acknowledge Chennai Metropolitan Water Supply \& Sewerage Board for providing sample and Chennai Mettex Lab Private Limited for analyzing the Toluene.

\section{REFERENCES}

[1] Farshid Ghorbani Shahna, Faride Golbabaei, Javad Hamedi,Hossein Mahjub, Hossein Reza Darabi and Seyed Jamaladdin Shahtaheri, "Treatment of Benzene, Toluene and Xylene Contaminated Air in a Bioactive foam Emulsion Reactor", Biotechnology and BioEngineeringChinese Journal of Chemical Engineering, Vol. 8, No. 1, Pp. 113-121, 2010.

[2] Wu-Chung Chan and Hui-Zheng You. "Nonionic Surfactant BriJ35 Effects on Toluene Biodegradation in a Composite Bead Biofilter", African Journal of biotechnology, Vol . 8, No. 20, Pp. 5406-5414, 2009.

[3] Byoung -Gi Park, Won Sik Shin ,and Jong Shik Chung, "Simultaneous Biofiltration of $\mathrm{H}_{2} \mathrm{~S}, \mathrm{NH}_{3}$ and Toluene using an Inorganic/polymeric
Composite Carrier", Journal of Korean Society of Environmental Engineers, Vol. 13, No. 1, Pp. 19-27, 2008.

[4] Gabriel Vigueras, Keiko Shirai, Daniel Martins, Telma Teixeira Franco, Luciana Fransisco Fleuri, Sergio Revah, "Toluene gas phase biofiltration by paecilomyces lilacinus and isolation and identification of a hydrophobin protein produced thereof", Applied Microbiol Biotechnol and Environmental Biotechnology, DOI 10. 1007/s 00253

[5] Yi, Chen Tsai, Chi, Mei Lee, Sz Chwun John Hwang, Meng, Yen Shih, "Addition of Rhodococcus Fascians AC6 to Prevent Inhibition of the Toluene Degradation from Ethyl Acetate in Biofiltration of VOCs Contaminated Air Stream", International Conference on Environmental Science and Engineering IPCBEE, Vol. 8, 2011.

[6] Seyed Morteza Zamir, Rouein Halladj, Bahram Nasernejad, "Removal of Toluene Vapors using a Fungal Biofilter under Intermittent Loading", Process Safety and Environmental Protection, Vol. 89, Pp. 814, 2011.

[7] Pakamas Chetpattananondh, Yada Nitipavachon, Charun Bunyakan. Biofiltration of Methanol and Toluene from waste gas, PSU-UNS International Conference on Engineering and Environment - ICEE-2005, Pp. 1-5, 2005. 